\title{
Distinguishing the innovation behaviour of micro, small and medium food enterprises
}

\author{
F. Minarelli ${ }^{1}$, M. Raggi ${ }^{2}$ and D. Viaggi ${ }^{1}$ \\ ${ }^{1}$ Department of Agricultural Sciences, University of Bologna, Viale Fanin, 44, 40127 Bologna, Italy; francesca.minarelli@unibo.it \\ ${ }^{2}$ Department of Statistical Sciences, University of Bologna, Via delle Belle Arti, 41, 40126 Bologna, Italy
}

OPEN ACCESS - RESEARCH ARTICLE

\begin{abstract}
The European economy, and particularly the food sector, is characterised by small and medium enterprises (SMEs). Networking represents for SMEs an opportunity to meet their needs in terms of know-how, and technological and financial resources with the main purpose of fostering innovation and facing global competition. Most scientific studies investigating networking for innovation focus on SMEs as a whole without exploring possible differences between SMEs. An important question to be posed is whether the firms within groups of SMEs behave the same in terms of innovation. The purpose of this paper is to understand whether different 'innovation profiles' of Italian food SMEs can be distinguished and to identify the structural factors associated with different profiles, with particular attention to size and networking. The methodology consists of a cluster analysis on data obtained by standardized on-line questionnaires compiled by Italian agri-food SMEs. Moreover, besides the identification of possible heterogeneity within the SME group with regard to innovation behaviour, the paper presents further value by providing useful information on surveyed Italian food SMEs in terms of firm structure and innovation.
\end{abstract}

Keywords: SMEs, innovation, network, food

Copyright: ${ }^{\circledR} 2014$ F. Minarelli et al. This is an open-access article distributed under the terms of the Creative Commons Attribution License, which permits unrestricted use, distribution, and reproduction in any medium, provided the original author and source are credited.

\section{Introduction and objectives}

The food industry is recognised as one of the most important sectors for the Italian economy, providing employment and relevant economic output. Even if traditionally considered in the literature as a low tech sector characterised by a poor level of research intensity and innovation (Christensen et al., 1996; Garcia Martinez and Briz, 2000), in recent decades, the increasing level of safety and quality standards in the food sector together with the globalisation of the food market (Galizzi and Venturini, 1996) have generated the need for technological inputs and hence a growing interest in promoting innovation in the agri-food sector (Traill and Meulenberg, 2002)

It is well known that the food industry is characterised by small and medium enterprises (SMEs) (Schiemann, 2008). Evidence from the literature (Roper, 1997) reports that SME businesses have distinctly different innovation behaviour compared to large enterprises, suggesting that an alternative approach needs to be taken for the former. Besides size, other factors have been recognised by the literature as having effects on innovation, such as participation in networks (Ahuja, 2000; Baptista and Swann, 1998; Powell et al., 1996) stages of product life-cycle (Pavitt and Wald, 1971) and level of internalization (Kafouros et al., 2008; Kirner et al., 2009; Wakelin et al., 1998). Starting with the first Schumpeterian hypothesis, in academic history, the size effect on innovation has always been the subject of thorough investigations. Yet studies have not reported conclusive results in this direction. In fact, several aspects affect the behaviour of the sizeinnovation relationship, and in particular a firm's sector (Acs and Audretsch, 1987). In this regard, food industry, studies have confirmed that larger firms are more innovative than smaller ones (Galizzi and Venturini, 1996; Huiban and Boushina, 1998). Not many authors (Colurcio et al., 2012; Triguero and Corcoles, 2013) have carried out studies on relationships between the size and innovativeness of food enterprises and even less have differentiated between micro, small and medium sized firms. 
In fact, to the best of our knowledge, few authors have explored the issue of size as a determinant of innovation within the food SME aggregate. The study reported by Turner et al. (2009) is the only one carried out on food SMEs that reports on the heterogeneity within SMEs in terms of innovation. This study explores how SMEs use projects, project management and the existence of size segmentation within SMEs aggregate. The results are based on data collected from a questionnaire that reported a response rate of the $20 \%$. The information is reported distinguishing micro, small and medium-size class based on employer number classification. The findings did not highlight meaningful differences in terms of investment in project managements among size classes. Moreover, the study confirms expectations that smaller companies can only afford the management of smaller size projects.

The literature offers other findings demonstrating that some studies were carried out within the SME aggregate. These deal with differences in firm behaviour with respect to risk exposure (Dietsch and Petey, 2004), information technology (Neirotti et al., 2013) public subsidies and project management (Alecke et al., 2012) but none of them is specifically carried out in the food sector.

Consequently, the issue of how and whether differences in innovation behaviour does indeed exist among medium, small micro enterprises in the food sector is mostly unexplored.

The purpose of this paper is twofold. First, it aims to understand what 'innovation profiles' can be recognised in a surveyed group of Italian food SMEs. Second, it investigates how they relate to structural factors, with particular attention on size, and networking. The study is innovative compared with the existing literature on several grounds. First, it applies to Italy, a country in which, to the best knowledge of the author, no similar studies have been undertaken to date. This is also relevant as the Italian food sector is rather unique and it can be expected that straightforward extrapolations from other areas provide misleading insights. In addition, compared with previous studies, this paper first recognises innovation profiles among the group of surveyed Italian food SMEs, and then checks for the existence of any connections with their structural features. This should make it possible to highlight whether Italian food SMEs can be treated as a homogeneous group or whether there are some relevant differences within subgroups of micro, small and medium sized enterprises in terms of their innovation behaviour. For such purpose a cluster analysis was carried out on surveyed data in order to group enterprises with similar innovation behaviour and distinguish emerging differences related to size.

This is expected to yield relevant insights into needs for policy differentiation among the group of food SMEs.

Two hypothesis are presented in the paper as a research framework:

- H1: the existence of heterogeneity within the food SME aggregate in terms of innovation behaviour which is highlighted through the cluster analysis.

- H2: the heterogeneity can be related to some firms' characteristic,s in particular the size, as reported in the literature review carried out in this section.

The paper is organised in five main sections, besides the present one. In Section 2 data collection and sampling is illustrated. Section 3 describes the data analysis methods. Section 4 illustrates the results, followed by a discussion in Section 5 and the conclusion in Section 6.

\section{Data collection}

The present work makes use of data collected through a web-survey developed for the European project NetGrow. While the survey addressed several European countries, in this paper we only use the results from the Italian part. Italian food SMEs were contacted by e-mails addressed to firm managers or CEOs. Each email provided a web link to have access to the web-survey.

Necessary e-mail contact information was partially collected from the AIDA database (Analisi Informatizzata delle Aziende). AIDA represents a broad database containing comprehensive information on some Italian companies, such as company name, financial information, corporate structure, street address etc. However, only some e-mail addresses were available for the firms listed in the database. Some missing email contacts were collected by internet searches and consequently added.

Within a total number of food 19,600 SMEs extracted from the database, 1,677 SME e-mail contacts were already available from the AIDA database and an additional 343 were located on the internet. The composition of the group of firms, in term of firm size, is composed of $23 \%$ micros $50 \%$ small and $25 \%$ medium sized firms.

The web survey compiling phase took place between October 2012 and March 2013. Forty- seven SMEs returned valid fully compiled questionnaires, Ninety were left incomplete. 
A Cluster analysis was carried out only on the completed section of questionnaires.

It must be said that in the composition of such a sample, which is $40 \%$ micro $43 \%$ small and $17 \%$ medium sized enterprises, the percentage of micro enterprises is overestimated. For this reason, the small number of respondents, the sample does not intend to be representative of the SME population neither carry out inference based on the results of the analysis. The purpose of the study was in fact of providing some evidences of heterogeneity within surveyed SME and relate them to firm's characteristics. The questionnaire was developed from previous academic reviews and output from a series of Delphi Rounds (Viaggi et al., 2012) and tested among the other European countries involved in the project.

The questionnaire is composed of two sections, one investigating on determinants and strategic behaviour of SMEs in networking and the other analysing preferences expressed by SMEs for some network types. In the first section, which represents the object of this analysis, respondents were asked to provide information in relation to the following factors: firm primary's geographical market, firm size, profit and employees trend in the last two years, firm's innovation strategy, innovation type (in terms of products process, markets and model business realized in the last two years) and their cooperative and networking behaviour with partners.

\section{Data analysis}

The data analysis was conducted in three stages, performing respectively: (1) descriptive statistics; (2) two step cluster analysis; and (3) crosstabs. In order to recognize innovation profiles among the SME surveyed, a cluster analysis was carried out. The innovation variables employed in the cluster classification are: innovation strategies, product innovation, process innovation, market innovation, business model innovation. Since we are dealing with qualitative variables, the Pearson's chi square was performed in order to test significant association between variables, in particular between firm's size and variables identified for the description of innovation profile, network participation and firm structure Variables describing the innovation profile in the web survey are shown in Table 1. Each of the four variables capturing the product, process, market and business model innovation was re-coded from a 7-point variable into a 5-point variable, depending on the number of innovations in the last two years $(0=$ no innovation, $1=$ 1 innovation, $2=2$ or more innovations, $3=$ don't know, $4=$ missing values).

Dealing with categorical and multinomial variables the Two Step cluster analysis was selected as the most appropriated procedure. The optimal cluster number was automatically determined generating 3 cluster profiles. Consequently, cross tabs were generated to add firm features descriptive of each cluster profile.

Table 1. Variable identifications: details of survey items used as variables.

Variable description

Type of variable

\begin{tabular}{|c|c|c|}
\hline \multicolumn{3}{|l|}{ Innovation variables } \\
\hline Product innovation & Number of new products realized in the last 2 years & Multinomial \\
\hline Process innovation & Number of new processes realized in the last 2 years & Multinomial \\
\hline Model innovation & Number of new business models realized in the last 2 years & Multinomial \\
\hline Market innovation & Number of new markets realized in the last 2 years & Multinomial \\
\hline Innovation strategy & First to market, not first but following rapidly, focus on niche market & Multinomial \\
\hline \multicolumn{3}{|l|}{ Firm's structure variables } \\
\hline Firm's size & $\begin{array}{l}\text { Micro (less than } 10 \text { employees), Small (10 to } 50 \text { employees), } \\
\text { Medium ( } 50 \text { to } 250 \text { employees) }\end{array}$ & Multinomial \\
\hline Firm's geographical market & Local, National, European, Global & Binary \\
\hline Participation to network & Industry associations, business club, clusters, technological parks & Binary \\
\hline Profit trend & Decreased, unvaried, increased & Multinomial \\
\hline Employment trend & Decreased, unvaried, increased & Multinomial \\
\hline Years in business & From how many years is the enterprise in business & Ordinal \\
\hline
\end{tabular}




\section{Results}

Details regarding the type and the description of variables used for the cluster analysis are reported in Table 1 . They are classified in innovation variables entered for the clustering analysis and firm structure variables adopted for the cross tab creation. Descriptive statistics of the forty seven SMEs are shown in Table 2. The table provides a general preliminary description of the frequency expressed by each modality of the surveyed variables: years in business, number of employees, trend of employment, participation in network, area of geographical market, innovation strategy, product innovation, process innovation, market innovation and model innovation. As it can be seen in Table 2, SMEs declare to have increased their profit in the last two years. Considering negative trends in the economy in the period in which the survey was carried out this is likely not in line with the general trends of many Italian SMEs. This underscores a possible bias in the sample, likely because enterprises with better performance can be more inclined to answer questionnaires of this kind. In addition, the very poor level of innovation in business models put in place by the SMEs surveyed should be noted. High innovation performance in markets is declared likely due to the perception of new opportunities by entering new markets. Table 3 reports the level of internalisation in relation to firm size. This table highlights some details in regard to the geographical market approach. It can be observed that a large portion of the SMEs in the sample count on international markets and few are active in local markets In particular, micros are more focused on local markets and the medium sized firms are those that mostly focus on the internalisation of their markets. Moreover, it should be noted that even if the modality of small enterprises is represented by the international market area, this class size shows a more homogeneous distribution compared to the other firm sizes. This behaviour is probably to be ascribed to the fact that within the class of small firms, firms closer in size to micro or medium size tend to behave similarly in these size classes.

Table 4 shows the output of the cluster analysis performed using the five innovation variables as discriminants and delineating the three innovation profiles matched with the firm structure modality for each cluster. Table 5 presents an in-depth description of each cluster composition.

As highlighted in Table 4, two patterns are clearly defined: cluster 1 and cluster 3 . Cluster 1 is characterised by small firms with higher innovation compared to the other two clusters. They are also more oriented toward the national market and try to be first on the market.
Table 2. Descriptive statistics of the small and medium enterprises (SME) survey group.

\begin{tabular}{|c|c|c|}
\hline Variable & Modality & $\%$ \\
\hline \multirow[t]{5}{*}{ Years in business } & $0-20$ & $23 \%$ \\
\hline & $21-30$ & $21 \%$ \\
\hline & $31-45$ & $21 \%$ \\
\hline & $46-70$ & $17 \%$ \\
\hline & $71-170$ & $17 \%$ \\
\hline \multirow[t]{3}{*}{ SME } & micro & $40 \%$ \\
\hline & small & $43 \%$ \\
\hline & medium & $17 \%$ \\
\hline \multirow[t]{3}{*}{ Trend of employment } & decreased & $13 \%$ \\
\hline & unvaried & $43 \%$ \\
\hline & increased & $45 \%$ \\
\hline \multirow[t]{3}{*}{ Trend of profit } & decreased & $15 \%$ \\
\hline & unvaried & $15 \%$ \\
\hline & increased & $70 \%$ \\
\hline \multirow[t]{2}{*}{ Participation to network } & in-network & $85 \%$ \\
\hline & out-network & $15 \%$ \\
\hline Local geographical market & & $17 \%$ \\
\hline National geographical market & & $34 \%$ \\
\hline European geographical market & & $23 \%$ \\
\hline Global geographical market & & $34 \%$ \\
\hline \multirow[t]{3}{*}{ Innovation strategy } & first to market & $34 \%$ \\
\hline & seldom first to market & $15 \%$ \\
\hline & focus on niche market & $51 \%$ \\
\hline \multirow[t]{5}{*}{ Innovation in product } & None & $23 \%$ \\
\hline & One & $19 \%$ \\
\hline & 2 or more & $47 \%$ \\
\hline & don't know & $9 \%$ \\
\hline & n.a. & $2 \%$ \\
\hline \multirow[t]{5}{*}{ Innovation in process } & none & $40 \%$ \\
\hline & one & $26 \%$ \\
\hline & 2 or more & $15 \%$ \\
\hline & don't know & $15 \%$ \\
\hline & missing data & $4 \%$ \\
\hline \multirow[t]{4}{*}{ Innovation in market } & none & $21 \%$ \\
\hline & one & $19 \%$ \\
\hline & 2 or more & $51 \%$ \\
\hline & $\begin{array}{l}\text { don't know } \\
\text { missing }\end{array}$ & $9 \%$ \\
\hline \multirow[t]{5}{*}{ Innovation in model business } & none & $55 \%$ \\
\hline & one & $19 \%$ \\
\hline & 2 or more & \\
\hline & don't know & $17 \%$ \\
\hline & missing data & $9 \%$ \\
\hline
\end{tabular}


Table 3. Geographical market area and size of small and medium enterprises.

\begin{tabular}{|c|c|c|c|c|c|c|}
\hline & Local & National & European & Global & Euro/Global & Nat/Euro \\
\hline Micro & $13 \%$ & $15 \%$ & $6 \%$ & $4 \%$ & $0 \%$ & $2 \%$ \\
\hline Small & $2 \%$ & $13 \%$ & $9 \%$ & $17 \%$ & $0 \%$ & $2 \%$ \\
\hline Medium & $2 \%$ & $2 \%$ & $0 \%$ & $9 \%$ & $4 \%$ & $0 \%$ \\
\hline
\end{tabular}

Table 4. Cluster profiles.

\begin{tabular}{|c|c|c|c|c|c|c|}
\hline Final clusters & \multicolumn{2}{|l|}{ Cluster 1} & \multicolumn{2}{|l|}{ Cluster 2} & \multicolumn{2}{|l|}{ Cluster 3} \\
\hline Number of cases per cluster & \multirow{2}{*}{\multicolumn{2}{|c|}{$\begin{array}{l}9 \\
\text { first to market }\end{array}$}} & \multicolumn{2}{|l|}{22} & \multicolumn{2}{|l|}{16} \\
\hline Innovation strategies & & & $\begin{array}{l}\text { first to mar } \\
\text { niche marke }\end{array}$ & /focus on their & focus on the & niche market \\
\hline New products & \multicolumn{2}{|c|}{ yes [2 or more innovations] } & \multicolumn{2}{|c|}{ yes [2 or more innovations] } & \multicolumn{2}{|l|}{ none } \\
\hline New processes & \multicolumn{2}{|c|}{ yes [2 or more innovations] } & \multicolumn{2}{|c|}{ yes [ 1 innovation] } & \multicolumn{2}{|l|}{ none } \\
\hline New markets & \multicolumn{2}{|c|}{ yes [2 or more innovations] } & \multicolumn{2}{|c|}{ yes [2 or more innovations] } & \multicolumn{2}{|l|}{ none } \\
\hline New Business models & \multicolumn{2}{|c|}{ yes [ 1 innovation] } & \multicolumn{2}{|c|}{ none } & \multicolumn{2}{|l|}{ none } \\
\hline Firm's structure & Cluster 1 & $\%$ per column & Cluster 2 & $\%$ per column & Cluster 3 & $\%$ per column \\
\hline Years in business & $21-30$ & $33 \%$ & $21-30$ & $18 \%$ & $31-45$ & $31 \%$ \\
\hline SME & small & $56 \%$ & small & $41 \%$ & micro & $50 \%$ \\
\hline Trend of employment & unvaried & $56 \%$ & increased & $59 \%$ & unvaried & $50 \%$ \\
\hline Trend of profit & increased & $78 \%$ & increased & $77 \%$ & increased & $56 \%$ \\
\hline Participation to network & in-network & $56 \%$ & in-network & $100 \%$ & in-network & $81 \%$ \\
\hline Internationalization & national & $44 \%$ & global & $59 \%$ & national & $50 \%$ \\
\hline
\end{tabular}

Cluster 3 shows a pattern characterised by micro firms producing no innovation, mostly oriented toward their niche market and operating at the national level.

Cluster 2 represents an intermediate level in which enterprises' innovation profile is characterised by having an equal frequency for two types of innovation strategies: being first to market and focusing on their niche market. These firms are slightly less innovative compared to those in cluster 1 and in fact they are particularly oriented toward global markets, probably thanks also to their intensive networking activities.

SMEs belonging to cluster 3, as already mentioned, do not produce innovation at all, but mostly participate in networks. This is in contrast with the suggested linkage between innovation and networking often postulated by research and policy; however, in the survey, in the question referring to networking, participation in networks for innovation purposes was not separated from participation in networks for other purposes. In this perspective, since the third cluster is characterised by micro sized firms, it is coherent that micro firms have more propensity to participate in networks, but likely for reasons not directly related to innovation.

An aspect emerging is that clusters 1 and 2, although both characterised a majority of small sized firms and similar innovation behaviour, show strong differences in their levels of internalisation. The first cluster consists of small firms oriented toward national markets, and the second has a global market focus. However, from the more accurate analysis of the cluster composition reported in Table 5, cluster 2 includes most of the medium size firms that, as shown in Table 3, are largely active on international (European and Global) markets. 
Table 5. Cluster descriptives.

\begin{tabular}{|c|c|c|c|c|c|c|}
\hline Firm's structure & Cluster 1 & $\begin{array}{l}\% \text { per } \\
\text { column }\end{array}$ & Cluster 2 & $\begin{array}{l}\% \text { per } \\
\text { column }\end{array}$ & Cluster 3 & $\%$ per column \\
\hline \multirow[t]{5}{*}{ Years in business } & $0-20$ & $11 \%$ & $0-20$ & $27 \%$ & $0-20$ & $25 \%$ \\
\hline & $21-30$ & $33 \%$ & $21-30$ & $18 \%$ & $21-30$ & $19 \%$ \\
\hline & $31-45$ & $33 \%$ & $31-45$ & $9 \%$ & $31-45$ & $31 \%$ \\
\hline & $46-70$ & $11 \%$ & $46-70$ & $14 \%$ & $46-70$ & $25 \%$ \\
\hline & $71-170$ & $11 \%$ & $71-170$ & $32 \%$ & $71-170$ & $0 \%$ \\
\hline \multirow[t]{3}{*}{ SME } & micro & $44 \%$ & micro & $32 \%$ & micro & $50 \%$ \\
\hline & small & $56 \%$ & small & $41 \%$ & small & $38 \%$ \\
\hline & medium & $0 \%$ & medium & $27 \%$ & medium & $13 \%$ \\
\hline \multirow[t]{3}{*}{ Trend of employers } & decrease & $0 \%$ & decrease & $9 \%$ & decrease & $25 \%$ \\
\hline & unvaried & $56 \%$ & unvaried & $32 \%$ & unvaried & $50 \%$ \\
\hline & increased & $44 \%$ & increased & $59 \%$ & increased & $25 \%$ \\
\hline \multirow[t]{3}{*}{ Trend of profit } & decrease & $11 \%$ & decrease & $14 \%$ & decrease & $19 \%$ \\
\hline & unvaried & $11 \%$ & unvaried & $9 \%$ & unvaried & $25 \%$ \\
\hline & increased & $78 \%$ & increased & $77 \%$ & increased & $56 \%$ \\
\hline \multirow[t]{2}{*}{ Participation to network } & in-network & $56 \%$ & in-network & $100 \%$ & in-network & $81 \%$ \\
\hline & out-network & $44 \%$ & out-network & $0 \%$ & out-network & $19 \%$ \\
\hline \multirow[t]{4}{*}{ Internationalization } & local & $22 \%$ & local & $5 \%$ & local & $31 \%$ \\
\hline & national & $44 \%$ & national & $9 \%$ & national & $38 \%$ \\
\hline & european & $11 \%$ & european & $27 \%$ & european & $25 \%$ \\
\hline & global & $22 \%$ & global & $59 \%$ & global & $6 \%$ \\
\hline
\end{tabular}

\section{Discussion}

This research underscores the heterogeneity of Italian food SMEs highlighted by the cluster process. The clusters analysed provide three innovation profiles, each one associated to different firm structures. The cluster profiles and their interpretation appear consistent with the existing literature.

The first cluster is characterised by small sized firms with high innovation performance focused on the national market. As confirmed by scientific literature, firms generating innovation do not feel obliged to export in order to reach new markets. Instead, firms characterised by low innovation performance need to look for new markets to be competitive (Wakelin, 1998). The second cluster presents another possible firm strategy, in which firms try to compete by focusing less on innovation in products and processes and more on fostering market innovation by introducing their products in new market areas. The third cluster includes SMEs that try to differentiate themselves by providing individually-tailored products or services for habitual costumers. This behaviour also finds support in the literature (Bennett and Smith, 2012) as a method adopted by small firms in order to be competitive.

In addition, the very poor level of innovation in business models applied by the SMEs surveyed should be noted. This should likely be ascribed to the simple structure of the SMEs and the fact that they tend to have less managerial and professional expertise (Thong et al., 1996).

Even though the response rate was rather low and the sample was likely not representative, the results show some different innovation profiles in the surveyed group and highlight the heterogeneity within the SME aggregate. In addition, the results yield new empirical information related specifically to Italian food SMEs. This is relevant, as previously stressed in the literature, as innovation can differ not only by industrial sector but also by countries (Alecke et al., 2012; Colurcio et al., 2012).

Moreover, by grouping SMEs through the cluster analysis it was possible to highlight some important aspects that can be retained as hypotheses for further research. The limited number of observations did not allow to use more sophisticated statistical techniques to carry out a 
more robust and accurate investigation of determinants of different innovation strategies. However, this is a common issue in most of the related empirical literature, which have been carried out based on case studies or on very small samples of firms. Also, some bias can affect the sample due to the self-selection process implied by the sampling modalities. In general this represents a difficulty observed in many case studies involving questionnaire submissions.

Finally, it can be stated that the questionnaire provided a satisfying amount of information related to innovation aspects and networking, in particular considering that questionnaire was mainly address to CEOs.

\section{Conclusion}

The analysis carried out refers to differences in the innovation profile detected within a group of questionnaire responses from food SMEs.

SMEs are a very heterogeneous group of businesses, particularly those operating in the food sector. They include a wide variety of firms such as winery, food-manufacturing, laboratories with high technological capacity and skills. Some are dynamic, innovative, and market-oriented while others are satisfied to remain small and family owned. It can be highlighted by the cluster profiling that not all SMEs have the same innovation behaviour in terms of generating innovation or innovation strategies. As noted, micro firms focusing on niche markets do not generate innovation, instead small firms tend to foster innovation and enter markets first. Medium size firms that do not represent the most numerous modality for any of the three cluster profiles, tend to be concentrated mainly in the second cluster profile.

In particular, the relationship between size and innovation is not straightforward. Not only the firm size but also the combination with other factors influence the innovation. In fact, as highlighted by the clustering micro and small firm sized show different innovation profiles.

The main policy message arising from this analysis is that different innovation strategies within SME categories need tailored policy instruments. In particular, consistent with firms' attitudes and innovation capability, it seems that some may benefit more from the design of proper innovation policy schemes, while others may benefit from the establishment of marketing support. Hence policies could also have a role complementary to the spontaneous patter followed by SMEs, by helping in developing strategies that are not implemented at the moment.
The heterogeneity within the SME classes captured by the cluster analysis remains a largely unexplored topic among academics. Even if the number of employees represents a common parameter for the classification, however, it represents a very approximate indicator for different and complex innovation behaviours. This study can be considered as a preliminary analysis for the development of indicators that allow for the identification of specific patterns that are typical for food SMEs. While this study does not yield more specific prescriptions for policy making, it highlights the relevance of further research specifically aimed at a more careful classification of the SME groups for support to innovation policy. Such insights would also represent an important input for the proper configuration of networks aimed at fostering innovation.

\section{Acknowledgement}

We acknowledge funding from the European Commission, $7^{\text {th }}$ Framework Programme through the project NetGrow (Enhancing the innovativeness of food SMEs through the management of strategic network behaviour and network learning performance, $7 \mathrm{FP}(\mathrm{KBBE})$, project number 245301. www.netgrow.eu). This work does not necessarily reflect the view of the European Union and in no way anticipates the Commission's future policy in this area.

\section{References}

Acs, Z.J., and D.B. Audretsch, 1987. Innovation, market structure and firm size. Review of Economics and Statistics, 69: 567-575.

Ahuja, G., 2000. Collaboration networks, structural holes, and innovation: a longitudinal study. Administrative Science Quarterly, 45: 425-455.

Alecke, B., T. Mitze, J. Reinkowski and G. Untiedt, 2012. Does firm size make a difference? Analysing the effectiveness of R\&D subsidies in East Germany. German Economic Review, 13: 174195.

Baptista, R. and P. Swann, 1998. Do firms in clusters innovate more? Research policy, 27: 525-540.

Bennett, R.J. and C. Smith, 2002. Competitive conditions, competitive advantage and the location of SMEs. Journal of Small Business and Enterprise Development, 9:73-86.

Christensen, J.L., R. Rama and N. von Tunzelmann, 1996. Innovation in the European food products and beverage industry. Industry studies of innovation using C.I.S. data. Aalborg, Denmark.

Colurcio, M., P. Wolf, P.Y. Kocher and T.R. Spena, 2012. Asymmetric relationships in networked food innovation processes. British Food Journal, 114: 702-727. 
Dietsch, M. and J. Petey, 2004. Should SME exposures be treated as retail or corporate exposures? A comparative analysis of default probabilities and asset correlations in French and German SMEs. Journal of Banking \& Finance, 28: 773-788.

Galizzi, G. and L. Venturini, 1996. Product innovation in the food industry: nature, characteristics and determinants. In: Galizzi, G. and L. Venturini (eds.) Economics of innovation: the case of food industry. Physica-Verlag, Heidelberg, Germany, 133-153.

Huiban, J.P. and Z. Boushina, 1998. Innovation and the quality of labour factor: an empirical investigation in the French food industry. Small Business Economics 10: 389-400.

Kafouros, M.I., P.J. Buckley, J.A. Sharp and C.Wang, 2008. The role of internationalization in explaining innovation performance. Technovation, 28: 63-74.

Kirner, E., S. Kinkel and A. Jaeger, 2009. Innovation paths and the innovation performance of low-technology firms - an empirical analysis of German industry. Research Policy, 38: 447-458.

Neirotti, P., E. Paolucci and E. Raguseo, 2012. Is it all about size? Comparing organisational and environmental antecedents of IT assimilation in small and medium-sized enterprises. International Journal of Technology Management, 61: 82-180.

Pavitt, K. and S. Wald, 1971. The conditions for success in technological innovation. Organisation for Economic Cooperation and Development, Paris, France, 169 pp.

Powell, W.W., K. Koput and L. Smith-Doerr, 1996. Interorganizational collaboration and the locus of innovation: networks of learning in biotechnology. Administrative Science Quarterly 41: 116-145.
Roper, S., 1997. Product innovation and small business growth: a comparison of the strategies of German, UK and Irish companies. Small Business Economics, 9: 523-537.

Schiemann, M., 2008. Unternehmen nach Großenklassen Uberblick uber KMU in der EU. Eurostat. Statisitk kurz gefasst 31. Europaische Gemeinschaften, Luxembourg, Luxembourg.

Thong, J.Y.L., C.-S. Yap and K.S. Raman, 1996. Top management support, external expertise and information systems implementation in small businesses. Information Systems Research, 7: 248-267.

Traill, W.B. and M. Meulenberg, 2002. Innovation in the food industry. Agribusiness, 18: 1-21.

Triguero, Á. and D. Córcoles, 2013. Understanding innovation: an analysis of persistence for Spanish manufacturing firms. Research Policy, 42: 340-352.

Turner, J.R., A. Ledwith and J. Kelly, 2009. Project management in small to medium-sized enterprises: a comparison between firms by size and industry. International Journal of Managing Projects in Business, 2: 282-296.

Viaggi, D., D. Cuming and M. Raggi, 2012. Deliverable 3.2b Comparative study of network attributes. NETGROW project: enhancing the innovativeness of food SMEs through the management of strategic network behaviour and network learning performance. Available at http://www.netgrow.eu/index. php?hova $=18$.

Wakelin, K., 1998. Innovation and export behaviour at the firm level. Research Policy, 26: 829-841. 